\title{
FOREST FIRE SCENARIO AND CHALLENGES OF MITIGATION DURING FIRE SEASON IN NORTH EAST INDIA
}

Kasturi Chakraborty ${ }^{1}$, Partho Protim Mondal, Mayuri Chabukdhara and S. Sudhakar North Eastern Space Applications Centre, Umiam, Meghalaya-793103,India

${ }^{1}$ Kasturi.nesac@gmail.com

KEY WORDS: Forest fire, North Eastern Region, Fire hazard map, fire mitigation, fire spread, DEM, shifting cultivation, MODIS

\begin{abstract}
Forest fires are a major environmental problem in North East Region (NER) with large tracts of forest areas being affected in every season. Forest fires have become a major threat to the forest ecosystems in the region, leading to loss of timber, biodiversity, wildlife habitat and loss to other natural resources. Studies on forest fire have reported that about $50 \%$ of forest fire in the country takes place in NE region. The forest fire in NER is anthropogenic in nature. The forest fire hazard map generated based on appropriate weightage given to the factors affecting fire behavior like topography, fuel characteristic and proximity to roads, settlements and also historical fire locations helped to demarcate the fire prone zones. Whereas, during fire season the weather pattern also governs the fire spread in the given area. Therefore, various data on fuel characteristics (land use/land cover, forest type map, forest density map), topography (DEM, slope, aspect) proximity to settlement, road, waterbodies, meteorological data from AWS on wind speed, wind direction, dew point have been used for each fire point to rank its possible hazard level. Near real time fire location data obtained from MODIS/FIRMSwere used to generate the fire alerts. This work demonstrates dissemination of information in the form of maps and tables containing information of latitude and longitude of fire location, fire occurrence date, state and district name, LULC, road connectivity, slope and aspect, settlements/water bodies and meteorological data and the corresponding rating of possibility of fire spread to the respective fire control authorities during fire season.
\end{abstract}




\section{INTRODUCTION}

Forest fire is considered a frequent and constant natural disaster in the forest ecosystems. The slash and burn shifting cultivation, or locally known as jhum the predominant form of agriculture in the hill tracts of North East India is found to be the major cause of forest fire in the region. The fires in the northeast India mostly pertain to slash and burn agriculture (Ramakrishnan,1988 and Majumder et al., 2011). In northeast India, indigenous institutions play an important role in forest management. About 9.8 million ha of forestland is under community control in the seven north-eastern states. Based on the information collected by Forest Survey of India officials in consultation with field officials of the State Forest Departments, the main reasons for the change in the forest cover has been summarized to be due to the shortening of the shifting cultivation and biotic pressure besides other reasons of encroachment and illicit felling (SFR,2011). These regions are also characterized by the high fuel loads (Baishya et al.,2009]. The history of incidence of forest fires in the state of Arunachal Pradesh has been studied between 1985 to 2005 and concluded that incidences of forest fire is related to increasing interference of human activities inside natural forest covers (Palit,2007).Increased incidences of forest fire have prompted government intervention and schemes aimed at preventing and controlling forest fire in Mizoram (Darlong,2001). In North Eastern India, satellite data observation reveal numerous fires in the Mizoram and surrounding Indian states of Tripura, Assam, Manipur, and along the border with Myanmar. A precise evaluation of forest fire problems and decision on solutions can only be satisfactory when a fire risk zone mapping is available (Jaiswal et al.,2002). Geospatial technology, including Remote sensing (RS) and Geographic Information Systems (GIS), provides the information and the tools necessary to develop a forest fire susceptibility map in order to identify, classify and map fire hazard area (Sowmya and Somashekar,2010). Geospatial modeling included a lot of information about the settlements, road, elevation and all the other parameters which are very useful when forest fire preparedness and management strategies are designed (Roy and Porwal,2005). This study aims to analyse the forest fire incidents in the past and its association with land use/land cover, topography and infrastructure and to generate a forest fire vulnerability map showing the proneness of the forests to forest fire hazard. With the help of such information forest fire mitigation strategies.

\section{Study area}

The study has been carried out in the North Eastern Region (NER) of India. The study area covers the seven sister states of NER viz., Arunachal Pradesh, Assam, Manipur, Meghalaya, Mizoram,

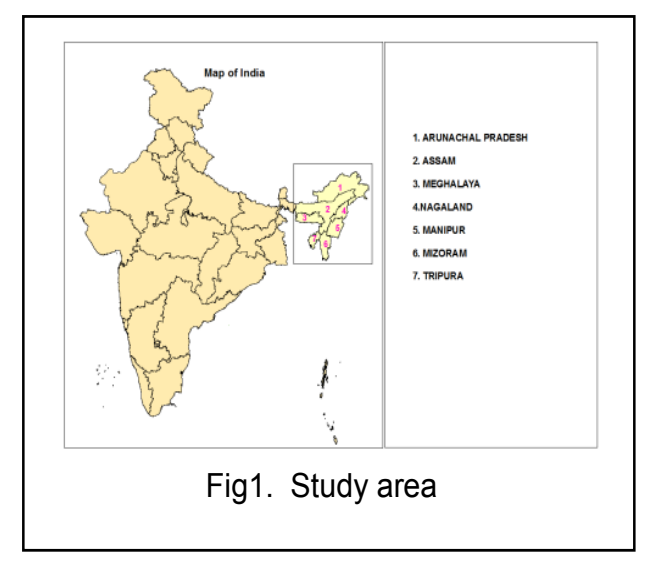


Nagaland, and Tripura (Fig.1). The state of Sikkim has not been considered in the study considering the low fire incidents in the region. NER covers about $8 \%$ of total India's size. The geographical coordinates of the study area is $90^{\circ} 26^{\prime} 0^{\prime \prime}$ to $97^{\circ} 33^{\prime} 0^{\prime \prime}$ and $21^{\circ}$ $50^{\prime} 0$ " to $29^{\circ} 27^{\prime} 30^{\prime \prime}$. The forests of NER are rich in biodiversity and timber. According to the India State of Forest Report, 2011North Eastern states that make up one-fourth of the country's forest cover. NER is one of the "biodiversity hotspots" in India. Various survey in this region reveal that the land is under heavy pressure due to jhum (shifting cultivation) for agriculture, the major land-use practice and facing frequent forest fire events.

\section{DATA USED AND METHODOLOGY}

Influencing factors like vegetation, topography, wind direction, proximity to village and road etc., have to be taken into consideration in identification of fire prone areas and their prioritization in forest fire risk zone mapping. The distribution of fire events derived from Forest Survey of India (FSI) was clipped to obtain the fire counts in the region. The forest fire risk map has been prepared with the following inputs:
Table 1: Themes and parameter used in the study

\begin{tabular}{|c|c|c|}
\hline $\begin{array}{l}\text { SI. } \\
\text { No. }\end{array}$ & Parameters & Classes \\
\hline \multirow{3}{*}{1.} & \multirow{3}{*}{ Vegetation } & Deciduous \\
\hline & & $\begin{array}{l}\text { Evergreen/Semi- } \\
\text { evergreen }\end{array}$ \\
\hline & & Pine/ Bamboo/Temperate \\
\hline \multirow{3}{*}{2.} & \multirow{3}{*}{ Vegetation Density } & Open \\
\hline & & Moderate \\
\hline & & Dense \\
\hline \multirow{5}{*}{3.} & \multirow{5}{*}{ Slope (degree) } & $15-25^{\circ}$ \\
\hline & & $25-35^{\circ}$ \\
\hline & & $8-15^{\circ}$ \\
\hline & & $3-8^{\circ}$ \\
\hline & & $0-3^{\circ}$ \\
\hline 4. & Aspect & $\begin{array}{l}\mathrm{N} / \mathrm{NE} / \mathrm{E} / \mathrm{SE} / \mathrm{SW} / \mathrm{S} \\
\mathrm{W} / \mathrm{NW}\end{array}$ \\
\hline \multirow{4}{*}{5.} & \multirow{4}{*}{ Elevation $(\mathrm{m})$} & $500-1000$ \\
\hline & & $1000-2000$ \\
\hline & & $200-500$ \\
\hline & & $0-200 />2000$ \\
\hline \multirow{4}{*}{6.} & \multirow{4}{*}{ Distance to settlement $(\mathrm{m})$} & $1000-1500$ \\
\hline & & $500-1000 / 1500-2000$ \\
\hline & & $0-500 / 2000-2500$ \\
\hline & & $2500-3000$ \\
\hline \multirow{4}{*}{7.} & \multirow{4}{*}{ Distance to road $(\mathrm{m})$} & $50-100 / 100-150$ \\
\hline & & $200-250$ \\
\hline & & $0-50 / 250-300$ \\
\hline & & $150-200$ \\
\hline \multirow{4}{*}{8.} & \multirow{4}{*}{ Distance to water bodies $(\mathrm{m})$} & $>1000$ \\
\hline & & $500-1000$ \\
\hline & & $300-500$ \\
\hline & & $0-100 / 100-200 / 200-300$ \\
\hline \multirow{2}{*}{9.} & \multirow{2}{*}{$\begin{array}{l}\text { Historical data and recent fire } \\
\text { events } \\
\text { (number of fire points) }\end{array}$} & $\begin{array}{l}\text { From January } 2001 \text { to } \\
\text { April } 2013 .\end{array}$ \\
\hline & & $\begin{array}{l}\text { Fire incidents of } 2014 \\
\text { used for validation of the } \\
\text { map. }\end{array}$ \\
\hline 10. & $\begin{array}{l}\text { Land use/land cover map } \\
(2005-06)\end{array}$ & $\begin{array}{l}\text { For removal of non-forest } \\
\text { area }\end{array}$ \\
\hline
\end{tabular}

Vegetation map (Forest / Fuel type) has been generated taking in account the vegetation characteristics like type and density. It is generated by reclassification of vegetation map into risk classes depending upon fire sensitivity. Elevation information is obtained from Digital Elevation Model (DEM). Slope is one of the important 
parameters that influence fire behaviour. Fire moves most quickly upward slope and least quickly downward slope (Jaiswal et al., 2002). With increase in angle of slope, fire risk increases. Hence, slope risk zone map has been generated from DEM. Aspect generated using DEM is another important parameter to be considered in fire mapping. Distance from roads and urban areas are important consideration because forest regions are more fire prone where they are located near to roads and high road density. We cannot use same weights and same variables indifferent regions because forest fire in each part of earth has its own characteristics. The fire points downloaded from NRSC,Bhuvan and FSI website are actually the fire points generated from MODIS data which uses brightness temperature derived MODIS $4 \mu \mathrm{m}$ and $11 \mu \mathrm{m}$ channels. The FSI, 2011 vegetation type and density map have been used for fuel characteristics, topographic information is generated from DEM (30m ASTER DEM) while available maps of road and settlement were used for proximity analysis.

Considering the uniqueness of location, vegetation type etc., of North Eastern Region, the given parameters has been analyzed separately for each state. Each of the theme/parameter has been classified into different classes as shown in table1. Appropriate weightages were applied to elevation, slope and aspect, vegetation type and density, the distance to settlement, road and water bodies. For the forest fire vulnerability mapping a decision making table was generated with the given parameters and historical data analysis of forest fire occurrence in each state. With the help of the above parameters and weights fire hazard zonation map is generated using multi-criteria decision analysis (MCDA) in GIS environment. Fire risk zones were classified into five categories, viz., very high, high, moderate, low and very low. The map shows the different zones with different level of proneness to forest fire. The definition of risk level (high, moderate and (ow) is a crucial subject to indicate the zonation showing high, moderate and low risk zones with regard to forest fire in the final fire risk map.

\section{RESULTS}

Based on the history of fire occurrence (from January 2001 to April2013), forest fire scenario in NER has been studied.Fig. 1 shows Mizoram is highly affected by forest fire. Fig2 and Fig.3 shows the fire prone zones of NER.

\section{Dissemination of forest fire risk alerts}

In addition to the ongoing forest fire alerts being provided everyday to the respective forest departments from authorized agencies, NESAC under its ongoing program of Disaster Risk Reduction in North East Region is issuing fire risk alert of each location in NER obtained from MODIS website everyday during fire season (Fig.4).

Most of the fire incidents in NER are anthropogenic in nature. To meet the challenges of forest fire mitigation activities in NER it is observed that during fire season it is very important to build a strong communication network between the forest departments and the community and the respective departments engaged in providing alerts. It is very important that the forest department and the local community are aware of the fire risk zones where forest 
fire can spread rapidly by taking up awareness programs. Since in this region forests are community controlled and fire are mostly occurring due to the shifting cultivation practice therefore, appropriate precaution needs to be taken up during fire season. There is a need for bringing up proper scientific knowledge. The forest departments and fire control authorities are required to be equipped with modern fire fighting instruments. The topography of the region is an important consideration in the fire mitigation. Therefore, the forest fire controlling authorities and communities should be aware of the alternate roads, nearest waterbody etc. It is very important that the fire in NER should be tackled with the community participation. The various information generated under scientific programs has to reach to the community level for better forest fire management.

\section{DISCUSSION}

The historical data analysis of the forest fire incidents in the region helped to understand the severity of the forest fire incidents in each north eastern state of India. The classification of the variable/parameter for zonation of fire proneness has been done depending on the history of fire incidents. Past studies on forest fire helped to form a knowledge base in defining the parameters. The climate data are important factors to be considered but it is found to play more important role during fire season.

The fire incidents are varying with fuel characteristics, topography and proximity to road and settlements with each region. The forest fire vulnerability map shows that large areas in NER are prone to forest fire. Five of the seven states have significant proportion of area under high risk zones. Tripura has approx. $52 \%$ followed by Nagaland $42 \%$, Mizoram 36\%, Manipur 35\% and Meghalaya $32 \%$ area under highly prone to forest fire hazard. Whereas, Arunachal Pradesh has maximum area under moderate hazard zone (44\%) and Assam has maximum low hazard zones. Mizoram has above $40 \%$ area under moderate vulnerability followed by Arunachal Pradesh, Manipur, Meghalaya and Nagaland. Contrary to the given facts, the observation of historical data of fire occurrence and the present scenario shows that Mizoram is facing maximum fire incidents $(31.38 \%)$ in the region in comparison to Manipur (approx.16\%), Assam (approx 15\%), Meghalaya (approx 12\%),Nagaland $(10.15 \%)$, Tripura $(9.16 \%)$ and Arunachal Pradesh (6.23\%). The number of forest fire points were compared with current shifting cultivation $(r=0.5)$ and abandoned shifting cultivation $(r=0.99)$ in Mizoram. The result indicates that most fire incidents are occurring in abandoned shifting patches along with other forest area. The forest fire incidents that occurred during 2014 have been compared with the vulnerability map that shows that most of the fire incidents have occurred in the high to moderate vulnerable areas.

The forest fire in the region has to be tackled with the help of community participation. 


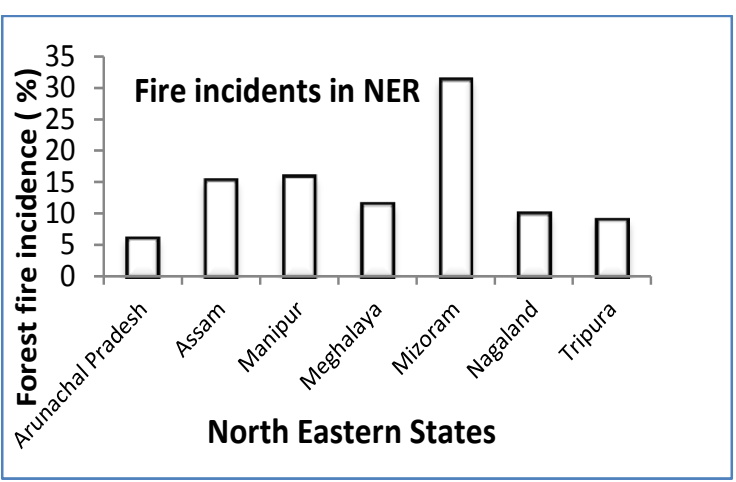

Fig1 . Fire incidences (\%) in Northeastern states in India (January 2001-April 2013)

Source: NRSC (January 2001-December 2010) and FSI (January 2011-April 2013)

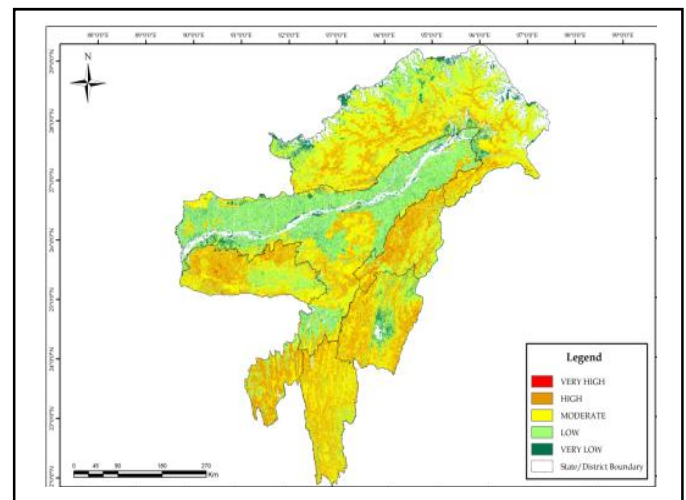

Fig.g.2 Fire vulnerability zones of NER

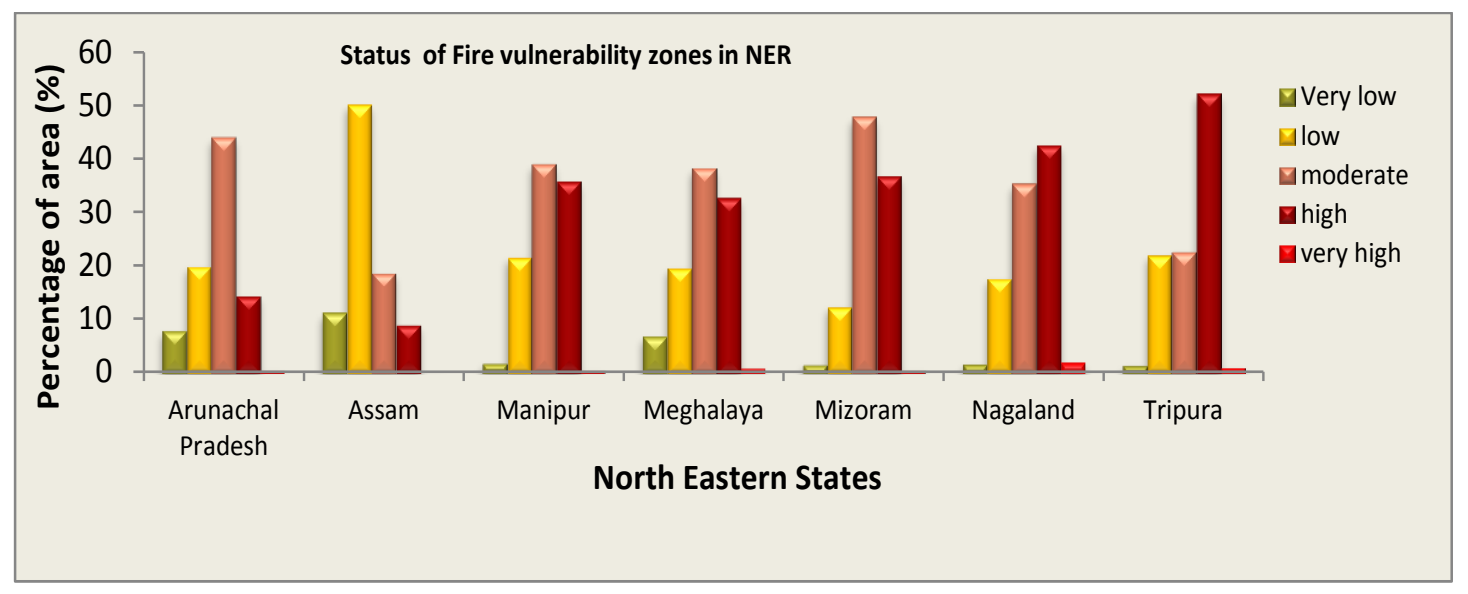

Fig3. Area-wise distribution of different fire hazard zones in NER

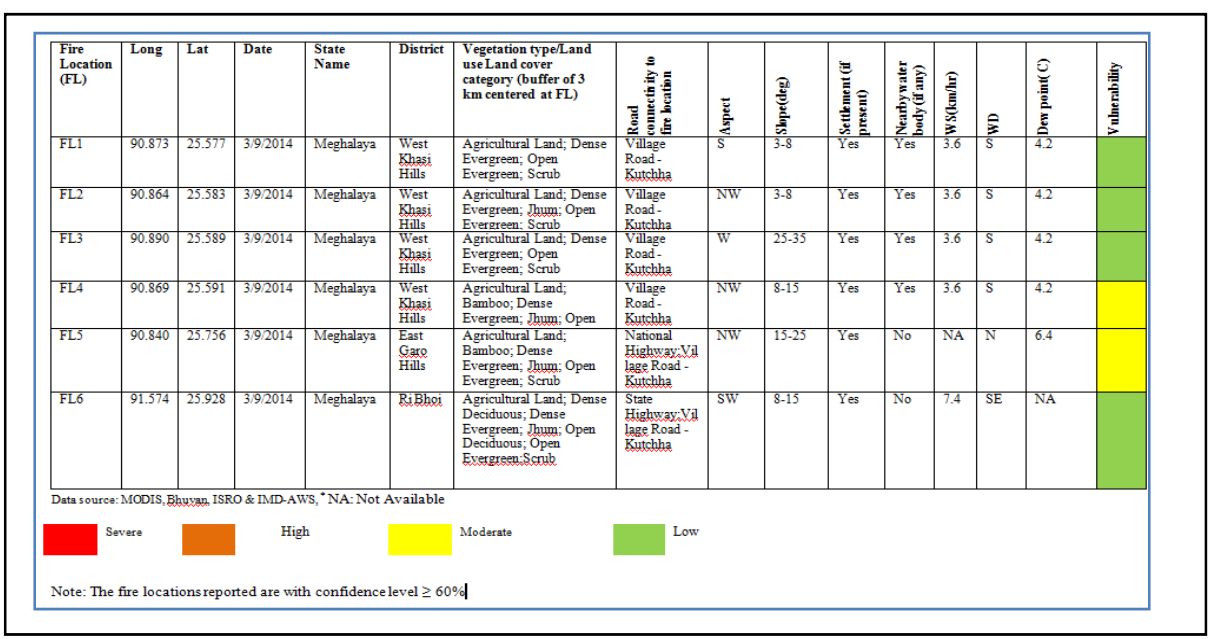

Fig.4 Sample table format of daily

forest fire hazard alerts 


\section{References}

Baishya R., Bari S. K., and Upadhaya K., 2009, "Distribution pattern of aboveground biomass in natural and plantation forests of humid tropics in Northeast India," Tropical E cology, vol. 50, no. 2, pp. 295-304,.

Darlong V T., 2001, Traditional community-based fire management among the Mizo shifting cultivators of Mizoram in northeast India, FAO corporate document repository.

FSI, State of Forest Report, 2011.Forest Survey of India, Dehradun, India.

Jaiswal R.K., Mukherjee S. , Raju K.D. , Saxena R. 2002, Forest Fire Risk Zone Mapping through Satellite Imagery \& Geographical Information System. International Journal of Applied Earth Observation and Geoinformation, Elsevier Publications, 4:1 -10.

Majumder M., Shukla A. K., and Arunachalam A., 2011 "Agricultural practices in Northeast India and options for sustainable management.Biodiversity, biofuels, agroforestry and conservation agriculture," SustainableAgriculture Reviews, vol. 5, pp. 287-315, 10.1007/97890481-9513-8-10.
Palit G.,2007,Forest cover and forest fires in eastern Himalaya: A study on ecological disaster with special reference to Arunachal Pradesh, PhD thesis.

Ramakrishnan P. S., 1988, "Sustainable development, climate change and tropical rain forest landscape," Climatic Change,vol . 39, pp. 583-600.

Roy N. and Porwal M C.,2005, Forest fire risk zonation using geo-spatial modeling in part of Rajaji National park, India, Asian Journal of Geoinformatics, Vol.5, No.3, p-40-46

Sowmya S V. and Somashekar,2010, Application of Remote sensing and geographical information system inmapping forest fire zone at Bhadra wildlife sanctuary, India, Journal of Environmental Biology, 2010, p-969-974

http://bhuvannoeda.nrsc.gov.in/disaster/disast er/disaster.php

http://www.fsi.nic.in/forestfire.php

\section{ACKNOWLEDGEMENT}

The authors are thankful to North Eastern Regional node for Disaster Risk Reduction (NER-DRR) program of NESAC sponsored by Dept. of Space, ISRO HQ, Banglore under which the study has been carried out. We are also thankful to the reviewers for valuable suggestions. 